\title{
Diálogo bioética-derechos humanos y ética civil en el ejercicio de la ciudadanía: caso comunidad LGTB*
}

\section{Dialogue bioethics-human rights and civil ethics in the exercising of citizenship: LGBT community case}

\section{Diálogo bioética-direitos humanos e ética civil no exercício da cidadania: caso comunidade LGTB}

\author{
Fecha de recepción: 15 de enero de 2016 \\ Fecha de evaluación: 9 de marzo de 2016 \\ Fecha de aceptación: 13 de abril de 2016 \\ Publicación en línea: 15 de abril de 2016
}

Nohora Joya Ramírez ${ }^{* *}$

DOI: http://dx.doi.org/10.18359/rlbi.1843.

Cómo citar:

Joya Ramírez, N. (2016). Diálogo bioética-derechos humanos y ética civil en el ejercicio de la ciudadanía: caso comunidad LGtB. Revista Latinoamericana de Bioética, 16(2), 40-57. Disponible en: <http://revistas.unimilitar. edu.co/index.php/rlbi/article/view/1843

Artículo de investigación producto de la tesis para optar el título de doctora en Bioética. Se inscribe en el Área de Bioética y Educación en línea de Desarrollo Humano. Directora Constanza Ovalle Gómez, PhD., profesora investigadora del Doctorado en Bioética de la Universidad El Bosque, Bogotá Colombia.

** Psicóloga; especialista en Docencia Universitaria, Investigación Social y Gerencia en Salud; magíster en Bioética y Sociología de la Educación; doctora en Bioética, de la Universidad el Bosque. Docente-investigadora, líder del grupo Procesos Psicosociales, Fundación Universitaria el Área Andina. Bogotá. Correo electrónico: njoya@areandina.edu.co. psicojoya@yahoo.com. ORCID: http://orcid.org/0000-0003-0284-4090. Bogotá, Colombia. 
Diálogo bioética-derechos humanos y ética civil en el ejercicio de la ciudadanía: caso comunidad LGTB

\title{
Resumen
}

Este artículo analiza los discursos del ejercicio de la ciudadanía en la comunidad LGTB a partir del diálogo bioética-derechos humanos. A través de un estudio cualitativo, enmarcado dentro del paradigma comprensivo permitió a partir de los actores reconocer las subjetividades e intersubjetividades. La comprensión del fenómeno en estudio requirió de una aproximación hermenéutica para ser descrita e interpretada a partir de entrevistas a profundidad a ocho sujetos de la comunidad LGTB a través de análisis del discurso. Así pues, se observó que el ejercicio bioético de la ciudadanía en la comunidad LGTB está permeado por una sociedad machista heteronormativa y las instituciones fundamentalistas no reconocen la ciudadanía plena de las personas LGTB, se imponen jerarquías y poder, y se expresan y enseñan el estigma y la discriminación hacia los hombres y mujeres con diversidad sexual. A partir de esto se concluyó que las sociedades patriarcales, heterosexistas, misóginas y homofóbicas expresan claramente jerarquías de poder, estigma y discriminación, y de esta manera se inhibe el ejercicio de la ciudadanía de las personas con diversidad sexual y de género.

Palabras clave: ética civil, bioética, derechos humanos, ciudadanía.

\begin{abstract}
This article analyzes the speeches of the exercising of citizenship in the LGBT community from bioethics human rights dialogue. Through a qualitative study, defined in the comprehensive paradigm that allowed from the actors, recognizing subjectivities and intersubjectivities. The Understanding of the phenomenon under study required a hermeneutical approach to be described and interpreted from depth interviews with eight people of the LGBT community through discourse analysis. Thus, we observed that the bioethical exercising of citizenship in the LGBT community is permeated by a heteronormative sexist society and fundamentalists institutions don't recognize the full citizenship for LGBT people, imposing hierarchies and power, and is expressed and taught stigma and discrimination against men and women with sexual diversity. Based on this, we concluded that patriarchal societies, heterosexist, homophobic and misogynistic, clearly express hierarchies of power, stigma and discrimination inhibiting the exercise of citizenship of people with sexual and gender diversity.
\end{abstract}

Keywords: civil ethics, bioethics, human rights, citizenship.

\section{Resumo}

Este artigo analisa os discursos do exercício da cidadania na comunidade LGTB a partir do diálogo bioética direitos humanos. Através de um estudo qualitativo, enquadrado dentro do paradigma compreensivo permitiu a partir dos atores, reconhecer as subjetividades e intersubjetividades. Para a compreensão do fenômeno em estudo foi necessária uma aproximação hermenêutica para ser descrita e interpretada a partir de entrevistas em profundidade com oito indivíduos da comunidade LGTB através de análise do discurso. Assim, observou-se que o exercício bioético da cidadania na comunidade LGTB é permeado por uma sociedade machista hétero normativa e as instituições fundamentalistas não reconhecem a plena cidadania das pessoas LGTB, hierarquias e poder são impostas, e expressam-se e ensinam-se o estigma e a discriminação para os homens e mulheres com diversidade sexual. Deste concluiu-se que as sociedades patriarcais, heterossexuais, homo fóbicas e misóginas expressam claramente hierarquias de poder, estigma e discriminação, e, portanto, o exercício da cidadania das pessoas com a diversidade sexual e de gênero é inibida.

Palavras-chave: ética civil, bioética, direitos humanos, cidadania. 


\section{Introducción}

En Colombia, Profamilia y la Universidad Nacional de Colombia, en 2009, publicaron un estudio sobre sexualidad y derechos, a través de cual encontraron que las personas "trans" son frecuentemente objeto de violencia y discriminación por parte de policías y agentes de seguridad privada, así: "por policía (78,7\%) y por personal de seguridad privada $(51,1 \%)$. [...] Los gay, a su vez, también reportan con frecuencia situaciones de discriminación por parte de policías. El 47\% del total de gais discriminados mencionan este tipo de problema" (Profamilia y la Universidad Nacional de Colombia y Centro Latinoamericano de Sexualidad y Derechos Humanos, 2009, pp. 104 y 105). El 25\% de los bisexuales y las lesbianas también reportan este tipo de violencia de género.

Por su parte, Catalina Lleras (2010), coordinadora del proyecto de derechos humanos de Colombia diversa, llamado Abuso policial: autoritarismo en la arbitrariedad legal, realizó una investigación entre 2008 y 2009 respecto del abuso policial y el autoritarismo, y encontró que esta conducta policial se presenta contra lesbianas, hombres gay, mujeres trans y defensores(as) de derechos humanos de la población LGBT. La investigación estableció que el abuso y el autoritarismo de los policías deviene en vulneración de los derechos humanos, tales como derecho a la libertad personal, derecho a la integridad personal y derecho al debido proceso como garantía del derecho a la verdad, la justicia y la reparación.
Se puede afirmar que existe un vacío frente al reconocimiento de la sexualidad diversa. Brigitte Baptiste (2005) expresa: "en otras palabras, el posicionamiento cultural de estas sexualidades corresponde a la necesidad urgente de reorganizar los sistemas bióticos bajo principios radicalmente distintos a los que el sistema de opuestos macho/ hembra posee" (p. 91).

Las heterodoxias sexuales se constituyen entonces en discursos de salvación [...] donde se manifiestan las fuerzas con las que se pretende conjurar la agresión y la violencia narcisista precedentes de la condición masculina; devolver la parafernalia erótica que la narrativa masculina le otorga a lo femenino [...] obligando a un reconocimiento y al establecimiento de un sistema de relaciones más sano, más equitativo, más placentero. (Baptiste, 2005, p. 97)

Lo más relevante de concepciones como la anterior es que la bioética desde su discurso incluyente permita que esta problemática de la comunidad LGBT no sea dirimida exclusivamente desde el derecho, como lo señala Escobar Triana, al plantear que no es conveniente solucionar estas dificultades solo con leyes, porque para que estas se respeten y se hagan válidas y sostenibles se requiere privilegiar los acuerdos y los consensos; los problemas deben "comprenderse para intentar su solución por medio de acuerdos y criterios éticos que faciliten el cumplimiento de esas leyes" (Escobar Triana, 2002, p. 14). La presencia de la 
bioética, como indica Escobar, genera esta exigencia: "se requiere una reflexión bioética, racional y laica, en la que intervengan los diferentes enfoques sobre la vida y las relaciones humanas que permitan vivir en comunidad" (2002, p. 15).

Se trata de hacer prevalecer en primera instancia el consenso ético como una herramienta garante de la sostenibilidad del respeto por una sexualidad diversa. Un escuchar plenamente, el pensar y el sentir de estas colectividades a propósito de la generación propia de una ciudadanía liberadora; para esto también es muy importante superar el discurso que la bioética ha tenido hasta el momento, pensando en ella como un campo interdisciplinar de discursos, saberes, epistemologías y prácticas (Escobar Triana y Aristizábal Tobler, 2011) que promueve el análisis, la discusión y la resolución de problemas éticos en las sociedades contemporáneas. De lo anterior es preciso señalar que los movimientos sociales han sido de vital importancia y se vislumbra que ha de seguir siendo de ese modo. Actividades memorativas como marchas, ciclos de arte, manifestaciones sociales han contribuido, pero el problema señalado es muy evidente todavía y exige nuevas prácticas y reflexiones.

Se propone, entonces, una reflexión puntual desde la bioética en general y la ciudadanía en particular. La bioética como modelo ético preservador de vida cualificada para todos lleva a consensos viabilizadores, entre otras cosas, del es- tado social de derecho y la justicia con inclusión social plena, es decir, ayuda a la disminución de las violencias de género y promueve el ejercicio de la ciudadanía. El objetivo del presente artículo es analizar los discursos del ejercicio de la ciudadanía en la comunidad LGTB a partir del diálogo bioética-derechos humanos.

\section{Metodología}

Se realizó un estudio de corte cualitativo, enmarcado dentro del paradigma comprensivo, que permitió a partir de los actores reconocer las subjetividades e intersubjetividades de estos. La comprensión del fenómeno en estudio requirió una aproximación hermenéutica para ser descrita e interpretada (Patton, 1990, p. 190). Dicha aproximación se hace también considerando las reflexiones hermenéuticas de Gutiérrez (1997) que subraya la declaración que hacen muchos profesionales, particularmente los antropólogos, de hacerse "militantes de la defensa de una forma de igualdad que sea garante de diversidad" (p. 73), pero fundamentalmente considerando el aporte de Martínez (2006) respecto del análisis del discurso: "El núcleo de estudio de todo análisis textual está en el siguiente hecho: el estudio no se refiere al texto en sí, a algo que esté dentro del texto, sino a algo que está fuera de él, en un plano distinto, es decir, a lo que el texto significa, a su significado" (p. 70) e incluso a las prácticas. En este estudio se tomó la hermenéutica en el sentido propuesto por Hans-George Gadamer. Entendida como la ciencia 
de la interpretación, tomando presente el contexto, el espacio, el tiempo y los actores, la hermenéutica permitió el acercamiento a la comprensión de las ciudadanías en los y las personas entrevistadas (Gutiérrez, 2008, pp. 71 y 72). La hermenéutica permitió construir el marco interpretativo de la investigación, que a su vez facilitó la interpretación, entendimiento y comprensión de los marcos interpretativos de la realidad de las personas esbozadas en sus discursos.

\section{Participantes}

El total de participantes fue de ocho personas, todas ellas advirtieron que no había inconveniente en utilizar su nombre verdadero en los relatos o la información expuesta; sin embargo, en aras de garantizar su integridad y evitar efectos adversos los nombres han sido cambiados. Es de anotar que todos los participantes residen en Bogotá y sus características se describen a continuación. Los y las participantes fueron en total ocho personas: dos lesbianas, dos gays (hombres homosexuales), un hombre bisexual y tres transgéneros (dos mujeres transgénero y un hombre transgénero). Todos los participantes tienen formación de educación superior: una persona con formación tecnológica y siete de ellas profesional. Las edades de los participantes oscilaron entre los 24 y 50 años.

\section{Técnicas e instrumentos}

Dada la complejidad del problema por investigar, la técnica implementada para la recolección de la información fue la entrevista a profundidad, partiendo del hecho de que, y de acuerdo con Bonilla y Rodríguez (2006), "quienes más conocen una situación particular son aquellas personas que cotidianamente la viven" (p. 163). Además, la entrevista permite a partir de preguntas abiertas y orientadoras obtener la experiencia del ejercicio de la ciudadanía desde cada uno(a) de los(as) actores, participantes en el estudio. Es importante resaltar, como lo plantea Gurdián-Fernández (2007, p. 198), que a través de la entrevista cualitativa los entrevistados se descubren a sí mismos y analizan el mundo y los detalles de su entorno, reevaluando el espacio inconsciente de su vida cotidiana, que en este caso giró en torno a sus vivencias respecto del ejercicio de la ciudadanía como representantes de la comunidad LGBT. La entrevista, en este caso, permitió la interacción, la creación y recreación de condiciones históricas y sociobiográficas determinadas. "Se trata de conversaciones profesionales, con un propósito y un diseño orientados a la investigación social, que exige del entrevistador gran preparación, habilidad conversacional y capacidad analítica" (Valles 2002, p. 41). En este sentido, la entrevista no solo permitió recolectar la información, sino también que los participantes, miembros de la comunidad LGBT, expresaran sus circunstancias históricas, sociales y biográficas relacionadas con el ejercicio de su ciudadanía, y a la investigadora el reto de interpretar, analizar y comprender en esos discursos y diálogos 
las nociones investigadas a la luz de la bioética y los derechos humanos. La guía de entrevista se constituyó como uno de los instrumentos, al igual que las diferentes matrices en las cuales se ubicó la información para el correspondiente análisis.

Las preguntas orientadoras que la constituyeron, ajustadas por categorías deductivas, plantearon algunos de los siguientes interrogantes: ¿qué conoce respecto de los derechos humanos? ¿Qué acciones o prácticas concretas considera que se deben implementar para proteger los derechos? ¿Cuál es su percepción sobre el ejercicio de los derechos en la comunidad LGBT? ¿Cree que las personas LGBT tienen iguales oportunidades que otras personas? ¿Cuál es su percepción sobre el ejercicio de la ciudadanía en la comunidad LGBT? ¿Cree que la discriminación por orientación de género afecta el ejercicio de la ciudadanía? ¿Cree que las personas LGBT tienen iguales oportunidades para ejercer su ciudadanía?

\section{Análisis de la información}

La herramienta interpretativa utilizada en esta investigación fue el análisis del discurso. "Es fundamental adoptar un enfoque de análisis discursivo para estudiar" (Van Dijk, 2007, p. 18) diferentes fenómenos, discriminación, racismo y, en nuestro caso, el ejercicio de la ciudadanía en la comunidad LGBT. El análisis del discurso permitió develar y comprender los mecanismos de poder que son utilizados socialmente, descubrir sus estructuras, estrategias y procesos, e incluso conocer aquellas de carácter sutil o enmascaradas. Con la información obtenida se procedió al "Análisis categorial relacionado". Para Lopera y Gutiérrez (febrero-marzo de 2010, p. 7), los documentos estudiados, tomando como referente un sistema categorial conformado por categorías principales, las cuales se subdividen en subcategorías y en algunos casos en descriptores.

Las categorías principales para esta investigación fueron deductivas, aunque emergieron algunas inductivas. El análisis de la información, para identificar en los discursos las diferentes manifestaciones de ciudadanía y sus significados, permitió, como lo expresa Álvarez Balandra: "situar a los conceptos y las tramas que con ellos se arman, como el instrumental cognitivo que sirve para reconocer la realidad interpretada, comprendida y explicada; claro está, integrados en una trama o red la cual es cohesionada por las categorías que sirvieron para su construcción" (2009, p. 96). Los niveles para realizar el análisis de la información fueron los siguientes:

1) Análisis textual, que consiste en la caracterización de la composición y estructura del discurso, centrándose fundamentalmente en el plano del enunciado y considerando el discurso en su dimensión de objeto de estudio. Puede realizarse a partir del análisis de contenido o del análisis semiótico. 
2) La primera operación del análisis textual suele ser, por tanto, la traducción de los discursos a una forma textual. Esta traducción de los discursos no textuales a una forma textual constituye ya una primera parte del análisis textual, lo que implica que deba realizarse según criterios y procedimientos rigurosos. Para ello, se utilizan dos procedimientos: la descripción, aplicada a los discursos no verbales, y la transcripción, aplicada a los discursos orales. El criterio fundamental es que esta traducción se realice de manera literal y detallada, lo que permite recuperar en la mayor medida posible todos los matices del discurso. Es importante resaltar que esta traducción de los discursos a una forma textual no solo es importante para el primer nivel del análisis, sino que también es fundamental para el análisis contextual y para la interpretación del discurso (Álvarez Balandra, 2009, p. 17).

3) El análisis contextual a partir de los procesos comunicativos intersubjetivos nos ofrece la comprensión del discurso, pues se centra en el plano de la enunciación y considera el discurso en su dimensión de hecho o acontecimiento singular. Por contexto se entiende el espacio donde el discurso ha surgido y donde adquiere sentido. Se trata, por tanto, de comprender los discursos como acontecimientos singulares, producidos por sujetos que se encuentran insertos en un espacio y un tiempo concretos, en un universo simbólico determinado y con intenciones discursivas propias. Desde este punto de vista, podemos distinguir dos tipos de contextos: el situacional y el intertextual, que dan lugar a dos tipos de análisis: el situacional y el intertextual (Álvarez Balandra, 2009, p. 12).

4) La interpretación busca ir más allá de los discursos, nos proporciona una explicación del discurso, considerando el discurso en su dimensión bien de información, bien de ideología o bien de producto social. Aunque la interpretación constituye un tercer nivel en el análisis sociológico del discurso, también está presente a lo largo de todo el proceso de análisis, es decir, en los dos niveles previos. Establecer un sistema de categorías para el análisis de contenido o establecer la estructura textual del discurso, por ejemplo, supone ya en cierto sentido una interpretación de este. Esto es así porque, como se señalaba antes, aunque la interpretación sea el último nivel de análisis y, por así decirlo, la culminación del análisis sociológico, este análisis se realiza en una constante y bidireccional comunicación entre los tres niveles definidos. La interpretación sociológica del discurso consiste en establecer conexiones entre los discursos analizados y el espacio social donde han surgido. 


\section{Consideraciones éticas}

En este estudio se tuvo presente la normatividad vigente para investigaciones con seres humanos, tanto las nacionales como las internacionales. En ese sentido y siguiendo la Resolución No. 008430 de 1993, del Ministerio de Salud de Colombia, según su artículo 11, esta investigación se consideró "sin riesgo". Es importante aclarar que aunque se realizó una entrevista a los participantes, esta no contenía preguntas que vulneraran la intimidad de las personas o generaran algún tipo de exaltación o cambio en su comportamiento. Acogió plenamente los principios éticos universales, como los planteados en la Declaración Universal sobre Bioética y Derechos Humanos, de la Unesco (2008), la cual en su artículo 9 exige el respeto a la privacidad así:

La privacidad de las personas interesadas y la confidencialidad de la información que les atañe deberían respetarse. En la mayor medida posible, esa información no debería utilizarse o revelarse para fines distintos de los que determinaron su acopio o para los que se obtuvo el consentimiento, de conformidad con el derecho internacional, en particular el relativo a los derechos humanos. (p. 8)

Su propósito o fin último fue contribuir al bien común, en especial de la Comunidad LGBT, así como al conocimiento de la bioética, teniendo en cuenta la reserva y confidencialidad de los participantes de la investigación. Se garantiza, entonces, la veracidad de los resultados y transparencia en todas las etapas del proceso. A pesar de ser una investigación sin riesgo, se realizó el proceso de consentimiento informado con los y las participantes en la investigación, advirtiendo que su participación es voluntaria (el formato de consentimiento informado se encuentra en el anexo 1). Durante dicho proceso se les explicó el objetivo y propósitos del estudio, los procedimientos, que en este caso es fue entrevista, y la manera como se haría la divulgación de los resultados y su veracidad. Es importante resaltar que la Declaración de Helsinki (Asociación Médica Mundial, octubre de 2013), según el artículo 36, plantea que los autores, directores y editores tienen la obligación ética de la publicación de los resultados de su investigación, los cuales deben ser veraces.

\section{Resultados}

\section{Ciudadanía, derecho a la vida y al trabajo: si no te echan por ser lgbt, te hacen la vida imposible}

Roxana es profesional en Gobierno y Relaciones Internacionales; trabaja como instructora para niños(as) de Kick boxing y se prepara para viajar fuera del país a cursar una maestría en Gestión Pública. Está comprometida con los derechos lgbt y se encuentra culminando un diplomado en construcción de identidad desde el cuerpo. 
Es una joven delicadamente femenina, finamente delgada y con una cultura a flor de piel; sentada en el sofá de su casa, narra poco a poco su construcción de mujer, sintiéndose bien como niño. Su construcción de identidad de género fue difícil, pues no se sentía bien siendo niña, pues es consciente de que no fue agresiva, y nunca fue del cuento de faldas y muñecas. En el Colegio no tuvo ninguna dificultad, siempre fue muy seria con el tema lgbt; le cuestionaban de pronto el tema de los novios, no más. Roxana observaba cómo "en sexto grado estaba de moda ser gay, al igual que en la época actual, pues escuchaba que las niñas de sexto referían ser gay por cuestiones de moda, más no había discriminación a pesar de ser el colegio católico", además "que veía como una niña en sexto si era claramente lesbiana con un lema que si lo eres estas inn, eran muy escandalosas con eso, más no vivieron bullying en ningún momento".

Cuenta que todo fue transcurriendo dentro de unos parámetros de normalidad, hasta cuando salió del colegio en el grado 11, que experimentó que se sentía bien siendo niño. En la universidad, en iv semestre, con 19 años tuvo una experiencia con una chica bisexual, con quien fue adentrándose en el mundo LGBT e inició un recorrido visitando bares y la cibercultura a través de los chats; sin embargo, no sabía cómo acercarse una niña, pues era tímida y por eso le pareció fácil internarse en el mundo del chat, desde donde conoció a sus primeras amigas. Todo ello transcurrió en tres meses aproximadamente, al cabo de los cuales le comentó a su madre su situación, hecho que le permitió tener seguridad, y obtuvo de ahí en adelante la facilidad de ser mujer lesbiana, pues para ella su mamá era muy importante.

Su proceso formativo en la educación superior le permitió ir haciendo una serie de análisis, a través de los cuales pudo ver cuánto se ha avanzado y al mismo tiempo los vacíos jurídicos frente a la normalidad o la composición de la familia. La Corte Constitucional ha asumido un papel importante al abogar por los derechos de la comunidad LGBT, como por ejemplo legislar sobre derechos de seguridad social, adopción, entre otros, y desde allí ella cuenta que no estamos tan mal como en otros países. En lo relacionado con el ejercicio de los derechos, dice que es más complicado el derecho al acceso laboral, "pues si no te echan por ser LGBT, te hacen la vida imposible, y es muy difícil comprobar que lo hicieron por esa condición, pues tendrían que tener testigos, y puede más el poder y las relaciones" (comunicación personal, 29 de septiembre de 2014).

Roxana manifiesta que hace falta mucha educación, pues no votamos, no se logran poner de acuerdo los sectores LGBT para elegir a un digno representante. Asimismo, recuerda el caso de Sergio, joven de 16 años que se suicidó recientemente, tras tener que enfrentarse a una estructura de poder desde un colegio, y que aunque tuvo el apoyo de los papás, "ino aguantó!, la salida para él fue no 
estar más en este mundo, pues a su novio lo obligaron a decir que estaba siendo acosado por él". En definitiva, hay mucha agresión y particularmente hacia las chicas "trans", pues las agreden en las cárceles, las meten en las celdas de los hombres, no reconocen la diferencia. También en salud se ven casos de violencia intrafamiliar, lo cual requeriría un trabajo sistémico, pero comprendiendo y conociendo el contexto de los LGBT, para los cuales se debe educar ampliamente.

Roxana, que continúa con bastante atención y compromiso su narración, expresa que el derecho más vulnerado es el derecho a la vida; si eres activista y defiendes los derechos de los demás, te pones en peligro: "con lo de las bacrin volvió a revivir lo de los panfletos, no solo fuera, sino en Bogotá" (comunicación personal, 29 de septiembre de 2014). Los grupos que ella considera más vulnerados son las mujeres "trans", pues no les dan trabajo amplio sino en ciertos espacios como las peluquerías. Por ejemplo, ella dice que ha trabajado con una líder "trans" denominada "Madona", quien dice que suelen etiquetarlas como personas agresivas, y que en los baños del barrio Santafé les han colocado sensores de metales.

Seguirían dentro de los más vulnerados los homosexuales, pues hay aceptación mayor hacia las lesbianas que sean femeninas, si dos niñas se ven agarradas de la mano lo ven bien, pero cuando son dos hombres que están en demostración afectiva cercana, ¡hay agresión fuerte y los atacan!
Continuarían después las lesbianas y luego los bisexuales, pues dentro de la comunidad se dice que si es bisexual está en transición y que debe definirse o que está en camino de ser gay. No les toman en serio porque les gustan los dos sexos y que por ende son más promiscuos y los agreden con comentarios (Roxana, comunicación personal, 29 de septiembre de 2014).

En lo relacionado con políticas públicas, dice Roxana que no están hechas para un grupo puntual, sino como garantías en general para todos(as), "son para que la población que tiene una problemática específica tenga las mismas coberturas de derechos que la saquen de esa vulnerabilidad" (comunicación personal, 29 de septiembre de 2014). En cuanto al ejercicio de la ciudadanía, afirma que las personas LGBT (no todos(as)) saben que es una política pública, no hacen ejercicio del voto; aunque reconoce que las marchas, las besatones y el activismo se han ido incrementado y estas prácticas favorecen a la ciudadanía. Reconoce también que desde el Estado y otros escenarios para la vida social se ejerce estigma y discriminación que no permiten ejercer la ciudadanía, por ejemplo:

Lo del monseñor procurador, pues se equivocó y debería ser defensor de los derechos humanos y del bien común, pero primó más su crucifijo en su oficina y ello ha generado una fuerte crítica; asimismo, lo sucedido en el centro comercial Avenida Chile, donde hicieron salir a una pareja gay por haberse besado. (Roxana, comu- 
nicación personal, 29 de septiembre de 2014)

Por otro lado, comenta que los colectivos se agarran de lo que más los identifica, se agarran de la mayor diferencia y allí cimientan su discurso; hay gente a la que no le gustan esas etiquetas. Quien trabaja con LGBT tiene que tener en cuenta todas esas diferencias, y esos discursos dejan reconocer que hay diversidad. Para Roxana las etiquetas tienen dos características: 1. etiquetas positivas o necesarias, de que somos diferentes, $y$ 2. etiquetas negativas que se usan de forma peyorativa y generan división.

Roxana con su mirada serena sigue contándonos su construcción como mujer desde niña sin faldas, ni muñecas y nos cuenta que se deben trabajar una serie de acciones como: 1. educar desde el momento cuando se nace; enseñar que te puedes enamorar de una persona como ser humano, más allá de si es gay, etc.; 2 . implementar la cátedra LGBT, buscando que se comprenda cómo dar a conocer sus diferencias; 3. abordar libros en los cuales se muestren familias diversas, así un niño desde chico reconoce que hay muchos tipos de personas, y eso no estaría mal; 4. trabajar por que el Congreso y el Gobierno tengan claridad en las apuestas con el sector LGBT; 5 . comenzar a cambiar la forma de enseñar, pues no serán las de acusar y matar al que piensa diferente. Debe haber políticas de choque, que aseguren derechos en diferentes contextos; 6 . formar a los docentes, pues (según recuerda Roxana) en 2008 se creó la cátedra LGBT para todos los colegios distritales, que estaba orientada a los estudiantes, pero no tuvo fuerza y sí se aplicó a los docentes con importantes resultados; 7. las familias necesitan acciones de formación, pero hay que tener cuidado, por las miradas de Gobierno al adentrarnos en las familias directamente; 8 . se debe trabajar no solo políticas públicas en Bogotá, sino también a nivel nacional, pues hay regiones machistas; 9. se debe llegar a todo campo relacionado con el conflicto armado.

En general, cuenta Roxana que el país latinoamericano más abierto a la mirada LGBT es Argentina, pues fue el primero en aceptar el matrimonio gay; también están México y Uruguay, y respecto a Brasil no se sabe muy bien cuál es la verdad. Donde más puede verse lo anterior en luchas LGBT es en las islas caribeñas. "En definitiva hay que trabajar por el primer gran derecho, que es el derecho a la vida, una vida digna, que dentro de todos esos derechos se encuentre el derecho a no ser discriminado" (Roxana, comunicación personal, 29 de septiembre de 2014).

\section{Discusión}

Las sociedades machistas heteronormativas y las instituciones fundamentalistas no reconocen la ciudadanía plena de las personas LGTB; imponen sus jerarquías y poder, expresan y enseñan el estigma y la discriminación hacia los hombres y mujeres con diversidad sexual. Es urgente la transformación de la sociedad y el ethos en sus distintos ámbitos (estatal, escolar, religioso, familiares) para 
que cada ciudadano pueda ejercer su derechos, "ser" y "hacer", desarrollar sus capacidades y llegar a ser un ciudadano del mundo.

\section{La ética civil como fin último del diálogo bioética-derechos humanos para favorecer la ciudadanía}

Martha C. Nussbaum (2005) expone como tesis principal el papel predominante que tiene la educación para la formación de ciudadanos del mundo, donde la identidad cultural, el respeto a la diferencia, la sensibilidad y la capacidad de comprensión juegan un papel primordial hacia el cumplimiento de esa particular forma de ciudadanía, lo cual sin duda genera una "ciudadanía de derechos". Por su parte, Victoria Camps, siguiendo el planteamiento de Ochoa (2009) expresa lo siguiente:

Parte de la existencia de una crisis de la ciudadanía y manifiesta que se trata de conseguir que los individuos se sientan realmente parte de un colectivo del que no sólo tienen derecho a reclamar prebendas, sino con el que les ate un compromiso. Las leyes no resuelven todos los problemas de los individuos; por ello, se proponen mecanismos que coadyuven a que el Estado, la familia, la escuela y la política se conviertan en ese vehículo para la formación ciudadana. [...] Por otro lado, en las escuelas se ponen de manifiesto las mismas prevenciones que asaltan a los padres ante lo que pueda parecer doctrinario y represivo; [...] la familia y la escuela deberían ser agentes complementarios no sólo en la adquisición de conocimientos, sino también en la adquisición de valores éticos y morales para el comportamiento tanto en la familia como en la civitas. (Ochoa, 2009, pp. 293 у 294)

Para Camps "la idea de educación para la ciudadanía responde a una serie de circunstancias críticas en el ámbito social y pretende aportar elementos para que las personas puedan ser realmente autónomas, con capacidad de discernimiento y de crítica" (Ochoa, 2009, p. 295). De esta forma, plantea que la educación debe propender hacia la consolidación de ideales o principios éticos, para lo cual también es necesaria la voluntad política y un Estado democrático.

Estas posturas teóricas son las que emergen en esta investigación desde la categoría ética civil. Es decir, una categoría planteada a partir de los miembros de la comunidad LGBT en aras de favorecer no solo su ejercicio ciudadano, sino también como promotora de una sociedad justa, incluyente, democrática y respetuosa entre sí.

La ética civil, en palabras de los participantes, asegura el respeto por los derechos humanos en contextos distintos, y para que ella sea una realidad es relevante el papel de la educación, pues a menor educación menor es el poder para exigir respeto por los derechos. Se observa, además, que para los 
participantes es importante trabajar en valores si queremos lograr una sociedad justa con parámetros de ética civil.

En congruencia con este hallazgo, Camps (2000) plantea que los seres humanos debemos educarnos y dar menor relevancia a dos valores que el sistema liberal ha impuesto: el éxito económico y el placer. En contraste, propone afianzar valores como la justicia (eje central de la ética), que a su vez incluye libertad, igualdad, tolerancia, paz y respeto por la dignidad humana.

Otra autora reconocida en este campo es Adela Cortina. Esta autora plantea en El mundo de los valores, que en Colombia antes de 1991 nuestra moral y nuestra ética estaban sujetas a la idea de Dios como creador de la humanidad y por tanto a quien se debe obediencia, y a la religión (judeocristiana) como la única válida para establecer las normas de acuerdo con los criterios divinos. Este panorama y actitudes siguen vigentes, ejemplo de ellos son las expresiones de Sonia: "Lograr tumbar tabúes que se tienen hacia los LGBT, pues los cristianos dicen que somos el demonio", "A los Trans los consideran la escoria de los homosexuales".

Es de resaltar que, siguiendo a Cortina, Dios no es ya el legitimador de la moral y la ética, ni el ser en virtud del cual se puede hablar de un orden moral único y establecido; por el contrario, se debe pensar en la existencia de una moral universal en aras de la justicia social; por esto, en la justificación de normas morales y jurídicas, la religión debe "ser sustituida por la razón" (Cortina, 2000, p. 75), pues "hay valores, actitudes, fines y metas que todos los hombres pueden y deben compartir" (Cortina, 2000, p. 76).

Después de la Constitución Política de 1991 en Colombia, Cortina (1998) plantea que:

El cambio más desconcertante en el mundo ético es, a modo de ver, el que se ha producido en las sociedades pluralistas al tener que decidir cuál es la instancia encargada de determinar qué es lo moralmente correcto. El paso del 'monismo' al pluralismo moral nunca se produce sin traumas, y éste es el caso de Colombia, así como de un buen número de naciones latinoamericanas. (p. 103)

Efectivamente, Colombia es una sociedad pluralista y Bogotá es un claro ejemplo de ello; dentro de este pluralismo encontramos la diversidad cultural y la diversidad de género u orientación sexual. Tomar en serio "el pluralismo moral supondría en verdad la convivencia - no la mera coexistencia- de distintas concepciones acerca de lo que hace felices a los hombres y acerca de lo que deben hacer; distintas concepciones acerca de lo bueno (lo felicitante) y lo justo" (Cortina, 2000, p. 73).

En sociedades como esta, los ciudadanos reales deben pensar más allá de su ética y moral individual, y en su lugar buscar lo común y lo colectivo. Para Cortina 
este cambio en el modo de pensar ético ayuda a "completar la ética individual con la ética de la acción colectiva" (1998, p. 106). Esto se relaciona con la solicitud que hacen los participantes de este estudio, a saber, diseñar unas políticas públicas incluyentes en las cuales queden plenamente incorporadas las perspectivas de los bisexuales y transgéneros, y no solo de los gays y las lesbianas. Una política centrada en la diversidad sexual, que permita el goce de los derechos para todas y todos, y que no esté enfatizada en individualidades, que para ellos son las que generan la endodiscriminación.

Para Cortina (1998):

Es preciso completar una ética de la buena intención individual con una ética de las instituciones y las organizaciones, ya que, en definitiva, nuestras acciones se mueven en el ámbito de la acción colectiva. El actual éxito de las éticas aplicadas caminan en este sentido: la ética de la empresa, de los medios de comunicación, de las profesiones. [...] En principio, propondría complementar la moral individual de la buena voluntad con una ética de las actividades sociales, concretamente de las profesiones. Es urgente, a mi juicio, fortalecer la moralidad de las sociedades desde las distintas profesiones que van componiendo parte esencial de la sociedad civil: desde la bioética, la ética de la empresa, la ética de los medios de comunicación, la ética de los jueces. (pp. 107-109)
Este fortalecimiento de la ética en las sociedades civiles es fundamental y debe pensarse en clave de la dignidad humana, la autonomía y la solidaridad. Esta llamada ética civil, tal y como lo proponen los participantes de esta investigación, debe promover el cambio en la forma de enseñar abandonando el énfasis en acusar y matar al que piensa diferente, para en su lugar fomentar la vida en comunidad. Además puede ayudar a exigir los derechos, desde la legalidad, respetando las posibilidades y las creencias del otro.

Como lo plantea Cortina (2000), con una ética civil o una moral civil, los seres humanos "aun cuando en nada comulgáramos, la vida en sociedad, regulada por normas consensuadas, nos proporciona más ventajas que el robinsonismo" (p. 77). Cabe resaltar que para la autora las virtudes que adornan a la ética civil son la tolerancia, la disponibilidad para el diálogo y aceptar el consenso, y el rechazo de hegemonías de poder.

En este sentido, la ética civil se presenta como un escenario de gran interés para la bioética, pues ayudaría a fomentar el diálogo y la búsqueda de consensos en medio de las grandes diferencias que nos separan en nuestra sociedad, para de esta forma erradicar fenómenos como las violencias de género y la estigmatización. Permitiría, también, que fuéramos ciudadanos capaces de entrar en un "diálogo público no solo para introducir temas en la agenda política, sino también para forjarse una conciencia moral 
y tomar decisiones morales" (Cortina, 2007, pp. 2-7).

Para Cortina la bioética en sociedades con pluralismo moral debe fomentar un uso público de la razón; por este motivo, se propone a la ética civil como fin último del diálogo bioética-derechos humanos, para favorecer a la ciudadanía, una ciudadanía argumentada, capaz de entender lo que nos une como género humano y respetar lo que nos diferencia a unos de otros, y también capaz de incentivar la participación en los planteamientos de políticas públicas, en aras de mediar y poner a dialogar la autonomía y la solidaridad.

Autonomía y solidaridad son entonces las dos claves de este personalismo dialógico, que rompe los esquemas de cualquier individualismo abstracto. Desde esa noción de sujeto, la exigencia de libertad o es universal o no es moral, la aspiración a una sociedad sin dominación es irrenunciable, la solidaridad es el humus desde el que un dividuo deviene persona, y sólo si alcanza a todo hombre puede reconocerse como auténtica solidaridad (Cortina, 2007, p. 111).

En este punto, podemos pensar como complementarias las propuestas de ética civil de Cortina con el cultivo de la humanidad y las capacidades de Nussbaum. Las diez capacidades centrales, cuyo eje articulador es la dignidad humana, contribuirían a fortalecer la idea de ética civil, en tanto la dignidad es un valor común a los humanos; asimismo, la autonomía y en conjunto todos anhelamos un mundo justo y solidario.

Por su parte, la ética civil aportaría al proyecto de las capacidades por cuanto prepararía a los hombres y mujeres, independientemente de su orientación de género, etnia o situación socioeconómica, para participar de la vida ciudadana, empoderarse de lo que quieren "ser" y "hacer", siempre haciendo eco del respeto por la diferencia y la diversidad de pensamientos.

Todas y cada una de las diez capacidades propuestas por Nussbaum solo podrán ser ejercidas por los seres humanos solo si tenemos una sociedad en que que cada uno de sus miembros puedan exigirlas, respetarlas y compartirlas, es decir, en una sociedad con una ética civil como brújula moral.

Las diez capacidades: vida, salud física, integridad física, sentidos, imaginación y pensamiento; emociones, razón práctica, afiliación, otras especies (relación próxima y respetuosa), juego y control sobre el propio entorno (político y material), según Nussbaum, pertenecen a las personas, son del orden individual, permiten considerar a cada persona como un fin en sí misma, que cada persona es merecedora de respeto y consideración. Sin embargo, todas las personas deben desarrollar de todas y cada una de estas capacidades, es decir, son un núcleo mínimo que se debe pensar en conjunto. 
Así pues, una sociedad bajo parámetros éticos compartidos, aunque con la posibilidad del disenso respetuoso, podrá permitir a los ciudadanos desarrollar sus capacidades y por tanto lograr ser ciudadanos del mundo; este es el ethos civitas que desde la bioética debe ser favorecido.

La bioética ha ayudado al empoderamiento del principio de autonomía al momento de tomar decisiones, especialmente en el ámbito de lo biomédico. Ahora, y dadas las exigencias de las sociedades del siglo xxi, debe promover una ética civil que promueva el respeto de esas autonomías, pero también que busque y afirme la importancia de lo colectivo, en un mundo cada vez más individualista. Una de estas búsquedas la ofrecen la dignidad humana y los derechos humanos, las capacidades propuestas por Nussbaum, y el desarrollo humano, que va más allá del desarrollo económico y el aumento de la propiedad privada y el poder.

\section{Conclusiones}

Las narrativas presentadas, análisis y disertaciones realizadas tocan temas álgidos para nuestra sociedad, recuerdan otros conocidos y nos dejan con la tarea y el compromiso de seguir trabajando, no solo por el reconocimiento de los derechos de las personas de la comunidad LGBT, sino también por las transformaciones pendientes en el sentido ético-político que amerita una sociedad incluyente y respetuosa de la diversidad sexual y su ciudadanía(s). Estas últimas no adscritas a sus acepciones tradicionales, sino encarnadas en el cuerpo y la sexualidad, y ejercidas en la vida cotidiana.

Las sociedades patriarcales, heterosexistas, misóginas y homofóbicas expresan claramente jerarquías de poder, estigma y discriminación, y de esta manera inhiben el ejercicio de la ciudadanía de las personas con diversidad sexual y de género. Solamente un ser humano podrá gozar de su ciudadanía cuando la sociedad permita la conjunción entre el ser y el hacer como humano. Para ello la ética civil, como fin último del diálogo bioética-derechos humanos, puede promover en todos los seres humanos el uso de argumentos en aras de lograr una sociedad justa, democrática, libre de estigmatización o discriminación, y permitir así la congruencia entre el ser y el hacer, es decir, dejando ejercer a la(s) ciudadanías posibles en sentido amplio.

\section{Referencias}

Alvarez Bandala, A. C. (2009). El corpus categorial y el método en la hermenéutica analógica para la interpretación de los procesos educativos [Tesis de doctorado].

Asociación Médica Mundial (octubre de 2013). Declaración de Helsinki. Principios éticos para las investigaciones con seres humanos. Recuperado en noviembre de 
2013, de http://www.wma.net/es/30publications/10policies/b3/

Baptiste, B. (Luis Guillermo) (2005). Sexualidad y ecofeminismo. En Bioética y sexualidad (p. 93). Bogotá: Ediciones El Bosque.

Bonilla Castro, E. y Rodriguez Sehk, P. (2006). Más allá del dilema de los métodos. Bogotá: Norma.

Camps, V. (2000). Los valores de la educación. (7ª edición). Madrid: Anaya. Recuperado el 10 de noviembre de 2014, de http:// bionotas.files.wordpress.com/2011/08/ camps-victoria.pdf

Cortina, A. (1998). El mundo de los valores. Ética mínima y educación. Bogotá: El Búho.

Cortina, A. (2000). Introducción a la filosofía práctica (6ta. Ed.). Madrid: Tecnos.

Cortina, A. (2007). Bioética y razón pública. Jurisprudencia Argentina, fascículo 6 (especial), 2-7.

Escobar Triana, J. y Aristizábal Tobler, C. (2011). Los principios en la bioética: fuentes, propuestas y prácticas múltiples. Revista Colombiana de Bioética, 6(especial), 76-109.

Escobar Triana, J. (2002). Bioética y conductas sociopáticas. En Bioética y conflicto armado (p. 14). Bogotá: Ediciones Universidad El Bosque.

Gutiérrez, C. B. (1997). Reflexiones hermenéuticas en torno de "ética y diversidad cultural”. En O. León (Comp.), Ética y diversidad cultural. México, D. F: Fondo de Cultura Económica.

Gutiérrez, C. B. (2008). Ensayos hermenéuticos. México, D. F.: Siglo XXI.
Lleras Cruz, C. (2010). Abuso policial: autoritarismo en la arbitrariedad legal. Recuperado el 15 de septiembre de 2011, de http://colombiadiversa.org/colombiadiversa/images/pdf/20082009capitulos/AbusopolicialpersonasLGBT20082009Colombia.pdf

Lopera Calle, M. P. y Gutiérrez Londoño, E. D. (febrero-marzo, 2010). Cartilla de Investigación. Investigación formativa: Orientación para la Formación de Proyectos de Grado Metodología. Centro de Investigación Escolme, 3. Recuperado el 15 de diciembre de 2012, de http:// www.itescam.edu.mx/principal/sylabus/ fpdb/recursos/r81860

Martínez Miguélez, M. (2006). Ciencia y arte en la metodología cualitativa. México, D. F:: Trillas.

Nussbaum, M. C. (2005). El cultivo de la humanidad. Una defensa clásica de la reforma en la educación liberal. Barcelona: Paidós Ibérica.

Ochoa Avalos, M. C. (2009). Reseña de "Educar para la ciudadanía" de Victoria Camps. Revista de Estudios de Género. La ventana, III(29), 292-297.

Patton, M. Q. (1990). Qualitative evaluation and research methods. Newbury Park: Sage.

Profamilia, Universidad Nacional de Colombia y Centro Latinoamericano de Sexualidad y Derechos Humanos (2009). Encuesta LGBT: sexualidad y derechos. Participantes de la marcha de la ciudadanía LGBT, Bogotá 2007. Recuperado el 15 de septiembre de 2011, de http:// www.artemisanoticias.com.ar/images/ FotosNotas/encuestacolombia.pdf 
Diálogo bioética-derechos humanos y ética civil en el ejercicio de la ciudadanía: caso comunidad LGTB

Unesco (2005). Declaración Universal sobre Bioética y Derechos Humanos. Recuperado en mayo de 2013, de http://unesdoc.unesco.org/images/0014/001461/146180S.pdf
Valles, M. (2002). Entrevistas cualitativas. Madrid: Centro de Investigaciones Sociológicas.

Van Dijk, T. A. (2007). Racismo y discurso en América Latina. Barcelona: Gedisa. 